\title{
Whose recommendations supplement users believe the most?
}

\author{
Suzana Miljković \\ Faculty of Pharmacy - Novi Sad, Trg mladenaca 5, 21000 Novi Sad, Serbia
}

\section{Introduction}

Food supplements are very attractive products for consumers of all age groups, with different life styles, health status, and various needs, and their use increasing among many populations in the world (Perlitz et al., 2019). According to the Directive 2002/46/EC: "food supplements are foodstuffs the purpose of which is to supplement the normal diet and which are concentrated sources of nutrients or other substances with a nutritional or physiological effect, alone or in combination, marketed in dose forms - capsules, pastilles, tablets, pills etc. designed to be taken in measured small unit quantities". These products are available in pharmacies and various shops, and consumers are freely to decide which product to choose and how to use it.

Information on their effects, properties, possible side effects and interactions with the drugs, food or other supplements, as well as suggestions on their selection and application are available from different sources: healthcare professionals (medical doctors, pharmacists), relatives, friends, media, social networks, etc. As this category of food is growing every year, and many new ingredients are introduced, a lot of them having a natural origin, consumers need to be properly informed. Due to application in pharmaceutical dosage forms, many users believes these products act as a drugs, it is important to encourage only the realistic expectations.

\footnotetext{
*miljkovicsuzana7@gmail.com
}

In order to achieve the desired outcomes of food supplements use, consumers should follow the healthcare professionals' advice. Pharmacists, with their professional expertise on the selling point, are well educated to give the proper recommendation for the selection, application and expected outcomes of the food supplements according to the needs of any user (Goundrey-Smith, 2018).

In this study, we analyzed the choice of sources of information of participants in 10 separate studies dealing the various food supplements use in Serbia, as well as the influence of pharmacist's advice on the consumers.

\section{Materials and methods}

This is cross-sectional study of 10 separate investigations on food supplements use, realized in several cities in Serbia. We analyzed only the results on one question in purposefully made questionnaires used in these studies: what are the most influential sources of information for the participants. Offered options were: doctor, pharmacist, relatives and friends, media and social media, others. We pay special attention on influence of pharmacist's advice on the consumers.

Results were presented in \%, as an average value of total number of participants. 


\section{Results and discussion}

There were total of 1459 participants, mostly women (65.7\%), with secondary level of education (52.9\%) and an average of 44.4 years. According to these results, women were more interested in their and the health of their family, they take more care about the use of supplements and more often than man buy these products. The studies were realized in Novi Sad, Belgrade, Kruševac, Požarevac and other cities in Serbia in the period 2017-2019. The food supplement categories, investigated in this 10 studies were: for immunity, dislipidemia, pregnancy and lactation, eyes, weight loss, products with zinc, magnesia, phytonutrients, antioxidants and probiotics.

Most of the respondents have chosen the recommendations of doctors (38.5\%) and pharmacists $(28.2 \%)$ as relevant for selection of this kind of products. This means $2 / 3$ of all respondents have chosen the advice of health care professionals, and we could say the recommendations they got were evidence-based and according to the exact needs of every consumer. This is the best choice, as there are many other sources of information where some important data could be omitted, or generated on the basis on irrelevant origin. Advice of gynecologists (67\%) and ophthalmologists (80\%) were the most important for users of food supplements for pregnant and lactating women, and eyes, respectively. This is quite understandable, as these consumers need the support for their regular treatment/therapy and asked for the physicians' opinion.

Relatives and friends were the chosen sources of information for $15.7 \%$ participants, media (printed, electronic media, social networks, etc.) were chosen by the $11.4 \%$ and others by $6.3 \%$ participants. As relatives and friends recommended products on the basis of their previous experience with effects of the product on their own problems, this kind of suggestions shouldn't be crucial for the decision. Anyway, their opinion was important for supplements with zinc $(28.3 \%)$ and phytonutrients (aronia) (28.3\%) users. Influence of media (TV, newspapers, internet) was important for consumers of antioxidants (26\%), and as a second choice, beside the doctor's advice, for pregnant and lactating woman (20\%). As a younger group of participants
(23-40 years old) it is expected they were looking for the information in media, but it was very important to discuss these data with their physicians, too.

Pharmacists' suggestions were the most important for $28.2 \%$ of consumers, mostly the users of food supplements for immunity (47.6\%), dislipidemia (40\%), and with magnesia (37\%). Supplements that support immune functions are among the best seller products, and their consumers often take them for "just in case" reason. Similarly, magnesia supplements are used for multitude of reasons, and the offer of this group of products is huge, no wonder users need a professional advice. Anyway, we believe the influence of pharmacists, and their recommendations on food supplements' consumers should be more pronounced. Through the communication and proper counseling the users, pharmacists should gain more interest and trust of the consumers.

\section{Conclusion}

Most participants of the studies used in this analysis, chosen the health care professionals as an adviser in food supplements selection and use. Although not quite relevant, an opinion of relatives, friends and media were also important for some respondents. Beside the doctors, pharmacists were the second most trustworthy source of information, but they should try to gain more trust by the consumers.

\section{References}

Directive 2002/46/EC of the European Parliament and of the Council of 10 June 2002 on the approximation of the laws of the Member States relating to food supplements. Official Journal of the European Communities, L 183/51.

Goundrey-Smith, S., 2018. The connected community pharmacy: Benefits for healthcare and implications for health policy. Front. Pharmacol. 9, e1352.

Perlitz, H., Mensink, G.B.M., Lage Barbosa, C., Richter, A., Brettschneider, A.K., Lehmann, F., Patelakis, E., Frank, M., Heide, K., Haftenberger, M., 2019. Use of vitamin and mineral supplements among adolescents living in Germany-Results from EsKiMo II. Nutrients 11(6), e1208.

Maced. Pharm. Bull. 66 (Suppl 1) 47 - 48 (2020) 